\title{
Aspectos psicossociais da parentalidade: $O$ papel de homens e mulheres na família nuclear
}

\author{
Psychosocial aspects of parenting: Men and women's role in nuclear families
}

\author{
Juliane Callegaro Borsa ${ }^{[a]}$, Maria Lucia Tiellet Nunes ${ }^{[b]}$
}

[a] Psicóloga, Mestre em Psicologia Clínica pela Pontifícia Universidade Católica do Rio Grande do Sul (PUCRS), Doutoranda em Psicologia pela Universidade Federal do Rio Grande do Sul (UFRGS), Porto Alegre, RS - Brasil, e-mail: psicojuli@yahoo.com.br

[b] Psicóloga, Doutora em Psicologia pela Universidade Livre de Berlim, professora titular da Faculdade de Psicologia, coordenadora do Programa de Pós-Graduação da Pontifícia Universidade Católica do Rio Grande do Sul (PUCRS), Porto Alegre, RS - Brasil.

\section{Resumo}

O presente artigo refere-se a uma discussão acerca dos aspectos psicossociais da parentalidade. Considerando a ênfase atribuída ao papel da mãe na família nuclear, em comparação com o papel do pai, foi realizado um levantamento de artigos sobre maternidade e paternidade em diferentes bases de dados online, com o objetivo de verificar a frequência de estudos publicados. Tal busca permitiu corroborar a expectativa de que, ainda hoje, os estudos sobre a relação mãe/filhos(as) são mais abundantes que os estudos sobre pais/filhos(as), reforçando a ideia construída socialmente de que as crianças devem ser cuidadas pelas mães, prioritariamente. Tal concepção, construída ao longo da história, acaba por diferenciar o papel de homens e mulheres na família contemporânea e, consequentemente, a maneira com que pais e mães se relacionam com suas crianças. Observou-se que, segundo a literatura específica sobre o tema, as concepções quanto ao lugar de homens e mulheres nas relações familiares são percebidas de maneira distinta, resultando em diferentes formas de relação e interação parental. Ainda hoje, a despeito das diversas mudanças ocorridas nos papéis sociais e na dinâmica das famílias contemporâneas, as mulheres ainda são vistas como as principais cuidadoras, sendo atribuído a elas o cuidado prioritário não apenas dos filhos, mas também do lar.

Palavras-chave: Parentalidade. Paternidade. Maternidade. Pai. Mãe. 


\begin{abstract}
This article aim to discuss the psychossocial aspects of pareting. Considering the emphasis on the mother's role in the nuclear family, in comparison to the father's role, a survey of articles about maternity and paternity, in different online databases was carried out, in order to verify the frequency of published studies. This survey corroborate the expectation that, even today, studies about mother/child relationship are more frequent than father/ child studies, reinforcing the socially constructed idea that children should be cared by their mothers, as a priority. This conception, constructed along the history, shows differences about the roles of men and women in contemporary family and consequently, the relation among parents and children. It was observed that, according to the literature about this subject, the conceptions regarding the role of men and women in family relationships are perceived differently, resulting in different forms of parental relationship and interaction. Even today, despite by several changes in social roles and dynamics of modern families, the women are still seen as the primary caregivers, being assigned to them, the priority care, not only to the children, but also to home.
\end{abstract}

Keywords: Parenting. Fatherhood. Motherhood. Father. Mother.

\section{Introduçáo}

O conceito comumente utilizado de família é oriundo de diversos aspectos sociais e culturais que se apresentam de maneiras diferentes sendo, portanto, instáveis e modificáveis ao longo do tempo, na medida em que os valores sociais também se modificam (De Marque, 2006; Silva, 2005). Embora não exista uma única definição sobre família, é importante salientar que os conceitos comumente trazidos estão diretamente relacionados ao modelo da família ocidental. Para o antropólogo e filósofo francês Lévi-Strauss (1972), do ponto de vista antropológico, o termo "família" é utilizado para definir um grupo social originado no casamento, constituído por marido, esposa e pelos filhos(as) provenientes de sua união, configurada a partir de três tipos de relações: aliança entre o casal (casamento ou legalização conjugal), filiação e consanguinidade. Já, segundo a concepção sistêmica de Minuchin (1982), a família é um grupo social cujos membros estão em constante interação entre si e com o ambiente, delineando, assim, o seu comportamento.

O modelo da família nuclear, constituído por pai, mãe e filhos(as), tem sido privilegiado na concepção construída historicamente sobre o grupo familiar-concepção prevalente que corresponde ao modelo hegemônico da família tradicional burguesa, monogâmica e patriarcal, oriunda da união de um casal por laços legais e legítimos (Silva, 2005; Szymanski, 1994). Nesse modelo, a mulher sempre ocupou um lugar fundamental, por meio do papel da maternidade, como um elemento agregador imprescindível para a sobrevivência da família (Flandrin, 1992; Duarte, 1995; Favaro, 2007).

No que se refere ao papel da maternidade, este foi impulsionado, ao longo dos tempos, por diversos aspectos sociais, políticos, culturais e religiosos (Costa, 1979; Ariès, 1981; Leite, 1994). Em função disso, o homem foi apoiado pela cultura ocidental que, sendo patriarcal, lhe reservou um lugar distante do contexto doméstico constituído, sobretudo, pela mulher e a criança (Gomes \& Resende, 2004). Tal cenário acabou por contribuir para que as relações entre pais e filhos(as) e mães e filhos(as) se tornassem quantitativa e qualitativamente diferentes (Silva \& Piccinini, 2007).

Assim, apesar das mudanças ocorridas na família contemporânea, a diferença de papéis entre homens e mulheres ainda é uma realidade, sobretudo no que se refere às famílias com menor poder aquisitivo (Luz \& Berni, 2010; Madalozzo, Martins \& Shiratori, 2008; Melo, Considera \& Sabatto, 2005; Soares \& Sabóia, 2007). O presente estudo tem como objetivo discutir a relação pais/ filhos(as) e mães/filhos(as), à luz dos aspectos psicossociais e culturais que implicam o exercício dos papéis exercidos por homens e mulheres o âmbito familiar e, sobretudo, no exercício da parentalidade.

\section{Diferentes concepçóes teóricas sobre o papel parental de homens e mulheres}

Conforme já referido, na família ocidental os papéis de homens e mulheres têm sido 
diferentes e essas diferenças se evidenciam, por exemplo, no fato de que o trabalho doméstico e o cuidado da prole continuam sendo atribuídos à mulher, prioritariamente (IBGE, 2006; Luz \& Berni, 2010; Madalozzo, Martins \& Shiratori, 2008; Piccinini, Silva, Gonçalves, Lopes, \& Tudge, 2004). Nos estudos sobre o desenvolvimento infantil, ainda hoje, o lugar do pai tem sido menos discutido quando comparado ao papel materno (Lamb, 1975; Luz \& Berni, 2010; Levandowski, Koller \& Piccinini, 2002). Essa realidade se repete no imaginário social acerca dos papéis de homens e mulheres no cuidado e na interação com suas crianças, o que acaba por contribuir para que exista maior interesse no estudo sobre o tema "mãe/maternidade" em detrimento do tema "pai/paternidade". Em um levantamento bibliográfico realizado por Levandowski (2001) nas bases de dados online, verificou-se que o número de artigos sobre maternidade é três vezes maior que o número de artigos sobre paternidade, considerando os achados internacionais publicados na década de 90. Contudo, na última década, os estudos sobre a paternidade vêm considerando a relevância da relação paterna, apontando para a importância de conhecer e compreender o lugar de um pai mais atuante e participativo. Esses novos estudos vêm sendo incentivados por um crescimento da popularidade do papel paterno como figura importante no desenvolvimento infantil. Os pais vêm afirmando o interesse de maior participação no cuidado e na criação dos filhos; como reflexo, os pesquisadores passaram a prestar mais atenção no papel do pai na família contemporânea (Crepaldi, Andreani, Hammes, Ristof \& Abreu, 2006; Luz \& Berni, 2010; Parke, 1998; Silva \& Piccinini, 2007; Resende \& Alonso, 1995).

Em que pese o crescente interesse pelo tema da paternidade, os estudos sobre maternidade ainda são mais numerosos. Tal fato pôde ser constatado em levantamento realizado, em maio de 2010, nas bases de dados online SciELO, Lilacs, Medline e PsycINFO, com os descritores "mãe/mother", "maternidade/ motherhood", "pai/father" e "paternidade/fatherhood". A busca de artigos publicados na última década, mediada pelos descritores em português e pelos descritores em inglês, apontam para a existência de três vezes mais publicações sobre mães e maternidade do que sobre pais e paternidade. Tal achado é congruente com os trazidos no estudo brasileiro de Levandowski (2001).
Conforme já referido, a cultura determinou, ao longo da história, os papéis de homens e mulheres na família. Nesse contexto, tornou-se relevante compreender essas relações e os aspectos emocionais envolvidos nas relações intrafamiliares (Badinter, 1985; Rocha-Coutinho, 2003; Mora, Otálora \& Recagno-Puente, 2005). Estudos sobre a importância do papel materno para o desenvolvimento infantil, sobretudo nos primeiros anos de vida, vieram dar conta de uma realidade existente e imperativa, ao mesmo tempo reforçando-a.

A psicologia fomentou, ao longo do tempo, a ênfase na relação da díade mãe/criança como primordial nos estudos de desenvolvimento da criança. Sendo atribuída menor importância ao pai no que tange ao desenvolvimento infantil, as teorias da psicologia acabaram por se ajustar ao tradicional conceito de um pai ausente e distante (Parke, 1998). Dentre as suas diversas correntes teóricas, a produção psicanalítica muito contribuiu para fazer da mãe o personagem determinante da saúde ou da doença psíquica da criança (Grant, 2001). No que se refere aos autores que contribuíram para essa ideia, é possível destacar Winnicott ([1987] 1998; [1958] 2000; [1965] 2001;), Spitz ([1965] 2000) e Bowlby (1989). Advindos da teoria psicanalítica, esses autores trataram sobre a relação materno-infantil, conferindo especial atenção às primeiras vivências e à formação do vínculo entre a mãe e o bebê, das quais emergem as relações ulteriores da criança (Borsa, 2007).

Conforme a teoria winnicottiana, por exemplo, é apenas por meio da presença da mãe continente e flexível que a criança pode iniciar um processo de desenvolvimento saudável. Essa concepção ilustra a relevância do papel materno no desenvolvimento saudável do bebê. Para esse autor, quando esse cuidado apresenta falhas que estabeleçam carências que não são corrigidas, o bebê poderá ter um comprometimento na constituição de sua subjetividade graças a essa deficiente relação materna (Winnicott, [1987] 1998; [1958] 2000; [1965] 2001).

É na tentativa de qualificar a relação mãe/ bebê e, sobretudo, enfatizar o papel da mãe no desenvolvimento infantil que Winnicott ([1965] 2001) propõe o conceito de "preocupação materna primária", ao caracterizar a atenção e o cuidado que a mãe dedica ao seu bebê. Esse conceito diz respeito ao estado psíquico atingido pela mãe saudável, colocando-a em posição de oferecer um ambiente suficientemente bom para o desenvolvimento das 
potencialidades inatas do bebê. Também sobre essa capacidade emocional da mãe, Spitz ([1965] 2000) traz o conceito de "clima emocional favorável", construído a partir da dedicação, do amor e do afeto da mãe para com o seu bebê, o qual é fundamental para o desenvolvimento deste; são os sentimentos maternos em relação ao filho que criam esse clima emocional, que servirá para orientar os afetos do bebê, conferindo-lhe qualidade de vida.

Por último, ao encontro das concepções de Winnicott e Spitz sobre a relação mãe/bebê, Bowlby (1989) aponta que as crianças que obtiveram um apego seguro com suas mães tendem a se tornar indivíduos sociáveis e autoconfiantes. No entanto, as crianças que não estabeleceram uma relação de apego satisfatória tendem a se tornar emocionalmente afastadas, ou mesmo hostis. De acordo com o autor, a interação do bebê com a mãe é a que exerce a maior influência no seu desenvolvimento, considerando que em todas as culturas conhecidas a grande maioria das crianças interage mais com a mãe do que com o pai.

Esses autores ilustram a concepção de que é esperada uma dedicação intensa ao bebê por parte da mãe, construída a partir de um amorincondicional, e que serve como base para um desenvolvimento saudável da criança ao longo de toda a vida. No entanto, apesar do apoio da literatura, a ideia da presença onipotente e do amor incondicional da mãe é passível de discussões, as quais se apresentam cada vez mais numerosas e contundentes.

Para as psicanalistas Badinter (1985) e Chodorow (1990), o amor materno é resultado de uma construção social e cultural, nada tendo a ver com instinto, fator sanguíneo ou um determinismo da natureza. Os argumentos de Badinter (1985) mostram que o mito do amor materno é recente. Anteriormente, a mãe possuía uma função mais biológica que afetiva, ficando as crianças a cargo de outros cuidadores que lhes garantiam a sobrevivência física e emocional. A crença do amor materno instintivo e incondicional trouxe importantes consequências no exercício da convivência entre pais e filhos(as) que persistem até os dias de hoje. Por diferentes razões, ainda hoje, pais e mães encontram dificuldades em abdicar da ideia da figura materna centralizadora e onipresente.

Para Chodorow (1990), a ideia da maternidade se dá por meio de processos psicológicos induzidos e reproduzidos socialmente. A autora sugere uma nova dinâmica na família, na qual as crianças poderiam estabelecer, desde o início, uma relação de igual dependência tanto com o pai como com a mãe.

De acordo com autores como Gomes e Resende (2004) e Silva e Piccinini (2007), a criança necessita do par conjugal para construir uma imagem positiva das relações afetivas e das interações sociais. Ao mencionar a denominação "par conjugal" torna-se necessário apresentar o conceito de coparentalidade, que se refere aos papéis de pais e mães exercidos em conjunto. O conceito de coparentalidade (coparenting) advém da teoria sistêmica e considera a relação pais/ mães/filhos(as). Consiste em um complexo sistema relacional de práticas e de modos subjetivos por meio do qual homens e mulheres criam os seus filhos (Nudler \& Romaniuk, 2005). A coparentalidade considera o relacionamento conjugal e a parentalidade uma vez que o primeiro influencia no segundo (Margolin, Gordis \& John, 2001; Talbot\&McHale,2004; Braz,Dessen \& Silva, 2005). Esse conceito diz respeito às figuras do pai e da mãe em exercício conjunto das suas funções parentais (Frizzo, Kreutz, Schmidt, Piccinini \& Bosa, 2005).

Para Mora et al. (2005), a supervalorização do papel materno impede, de certa forma, que os pais assumam, em conjunto, as funções parentais. Uma vez cedido o espaço exclusivo atribuído às mães, os pais poderiam adquirir maior proximidade com os filhos e nessa perspectiva haveria uma distribuição mais equilibrada dos papéis maternos e paternos. Contribuição importante sobre esse aspecto é trazida por Ramires (1997, p. 94). Para a autora, existe no imaginário social a imagem de que a relação pai e filho(a) depende e é oportunizada pela mãe. Os pais ainda conservam aideia acerca da maior importância da relação mãe e filho(a) em detrimento da relação pai e filho(a). As mães, por sua vez, apresentam certa resistência em abrir mão do "monopólio da maternidade", já que se trata de uma função feminina importante e socialmente valorizada. Em outras palavras, de acordo com a autora, ao mesmo tempo em que as mulheres reivindicam maior participação dos homens nas tarefas domésticas e cuidados dos filhos, elas ainda demonstram resistência e ambivalência quanto a dividir e compartilhar com o pai de sua criança.

\section{O papel de pais e máes na família contemporânea}

Apesar de tidas como tradicionais, as funções parentais de homens e mulheres nem 
sempre foram entendidas da maneira como são hoje. A atribuição da função de provedor ao pai e a glorificação da maternidade são relativamente recentes, reforçadas especialmente nos séculos XVIII e XIX. Antes disso, o cuidado da prole era apenas uma das tantas tarefas atribuídas à mulher que, assim como o homem, era responsável pelo provimento da família (Badinter, 1985; Rocha-Coutinho, 2003).

Até meados dos anos 50, o pai era considerado único responsável pelo sustento da família, enquanto a mãe responsabilizava-se por todas as atividades referentes ao lar e à família. Esse modelo de organização familiar permanece até hoje em muitos contextos, porém, trata-se de um cenário que vem sendo modificado pelas transformações que a família vem sofrendo ao longo do tempo (Lamb, 1975; Parke, 1998; Crepaldi et al., 2006).

Inúmeras mudanças ocorridas no século $\mathrm{XX}$, decorrentes de movimentos sociais como o movimento feminista, alteraram a identidade e o lugar da mulher na família, que, por sua vez, vem sofrendo constantes mudanças nas suas configurações (Badinter, 1985; Rocha-Coutinho, 2003; De Marque, 2006). Neste início de século XXI, observase que homens e mulheres vêm contribuindo para o estabelecimento de novas formas de relações no contexto sociofamiliar contemporâneo (Negreiros \& Féres-Carneiro, 2004). Com a consolidação das mulheres no mercado de trabalho e sua maior participação no sistema financeiro familiar, já é possível perceber uma relativa divisão de tarefas, na qual pais e mães compartilham aspectos referentes às tarefas educativas dos filhos e à organização do dia a dia da família (Fleck \& Wagner, 2003; Wagner, Predebon, Mosmann \& Verza, 2005).

Segundo Levandowski, Koller \& Piccinini (2002), essas mudanças muitas vezes remetem os homens ao exercício de funções do cuidado da prole e com a casa, que antes era de domínio exclusivo da mulher. Contudo, apesar das mudanças relativas à família contemporânea, a tarefa de acompanhar o cotidiano das crianças ainda é atribuída à mãe e não ao pai (Wagner et al., 2005). Nos tempos atuais, o lugar de homens e mulheres no âmbito familiar ainda parece definido pelos moldes arcaicos: às mulheres cabe o cuidado da prole, aos homens o papel coadjuvante nesses cuidados. Estudos realizados em diferentes países apontam para o fato de que, até recentemente, tanto os homens como as próprias mulheres ainda acreditavam que a casa e os filhos são responsabilidades da mulher, enquanto que o provimento financeiro da família seria responsabilidade do homem (Rocha-Coutinho, 2003).

Em pesquisa realizada pelo Instituto Brasileiro de Geografia e Estatística (IBGE), publicada no ano de 2008, nas chamadas famílias nucleares brasileiras, a realização dos afazeres domésticos está principalmente na mão das mulheres. Esse estudo mostrou alguns aspectos da desigualdade de gênero intrínseca ao âmbito da família no que se refere à realização do trabalho doméstico e do cuidado da prole. Nos modelos contemporâneos de família nos quais os comportamentos sociais já sofreram grande influência das novas relações de gênero, ainda se confirma uma forte presença das mulheres como responsáveis no cuidado do lar e da prole (IBGE, 2006; 2008; Soares \& Sabóia, 2007). Essa realidade pode ser considerada como um produto de um cenário ainda presente, no tocante às diferenças nas remunerações de homens e mulheres atuantes no mercado de trabalho (Melo, Considera \& Sabatto, 2005).

Estudo realizado por Madalozzo, Martins $\&$ Shiratori (2008) apontou que o volume de trabalho doméstico realizado pela mulher está diretamente relacionado ao seu rendimento econômico. A participação das mulheres no mercado de trabalho promove maior equidade nos papéis de gênero e consequentemente nas tarefas realizadas por homens e mulheres, nos mais diversos âmbitos. Em outras palavras, segundo os autores, a participação da mulher no mercado de trabalho, não somente com relação ao tempo dedicado a ele, mas, principalmente, com o aumento de sua remuneração diante do total da renda familiar, impacta positivamente sua condição de barganha na família, implicando uma menor participação no trabalho doméstico.

Segundo a pesquisa do IBGE sobre os principais destaques da evolução do mercado de trabalho nas principais regiões metropolitanas do Brasil, o rendimento de trabalho das mulheres continua sendo inferior ao dos homens. Em 2007, comparando a média anual dos rendimentos dos homens e das mulheres, verificou-se que, em média, as mulheres ganham em torno de $70 \%$ do rendimento recebido pelos homens.

Mesmo nos casos de mulheres participativas no mercado de trabalho, as tarefas domésticas ainda são consideradas de sua responsabilidade. Em outra recente pesquisa realizada pelo IBGE, 
observou-se que a crescente participação das mulheres no mercado de trabalho não reduziu a jornada delas com os afazeres domésticos. Ao contrário, na faixa etária de 25 a 49 anos de idade, em que a inserção das mulheres nas atividades remuneradas é maior e que coincide com a presença de filhos menores, o trabalho doméstico ocupa 94\% das mulheres. Ainda, segundo a pesquisa, a jornada doméstica tende a ser maior quando a renda familiar é mais baixa e quando os filhos são pequenos (IBGE, 2006; 2008; Soares \& Sabóia, 2007). Assim, é possível compreender os diferentes lugares ocupados por homens e mulheres e seus diferentes papéis na família contemporânea.

Quanto à dificuldade existente para atribuir um lugar à figura paterna, Tubert (citado por Mora et al., 2005) afirma que a paternidade é uma construção cultural que não se pode compreender sem articulação com a maternidade, no sistema parental e no universo simbólico da cultura em que se está inserido. As diferentes formas de parentalidade e suas mudanças ao longo do tempo estão associadas ao conceito e às mudanças relativas à ideia de masculino e feminino. Assim, o conceito de parentalidade não pode ser definido sem considerar o seu contexto relacional (Nudler \& Romaniuk, 2005).

A maternidade e a paternidade são construções de múltiplos significados para homens e mulheres. À complexidade da origem dos significados atribuídos aos filhos, são agregados outros elementos familiares, sociais e culturais e todos esses elementos agem conjuntamente. Por intermédio das experiências cotidianas dos diferentes membros da família é que surge um conjunto de expressões cujo sentido dá forma à relação, na qual é permitido significar o(a) filho(a) com diversas matizes, dependendo da voz que fala, o pai ou a mãe (Mora et al., 2005).

Diferentes relações parentais resultam em diferentes formas de perceber e compreender os filhos. Essa realidade pode ser verificada no estudo realizado por Borsa \& Nunes (2008), o qual objetivou analisar a concordância entre respostas de pais e mães relativas aos problemas de comportamento do mesmo filho por meio do instrumento Child Behavior Checklist (CBCL-6/18). Participaram desta pesquisa, 146 casais, com filhos de seis a dez anos, não clínicos, estudantes do ensino fundamental de Porto Alegre, RS, Brasil. As respostas ao CBCL classificam a criança como clínica ou não clínica nas escalas de competência social, problemas internalizantes, problemas externalizantes e problemas totais de comportamento. A concordância entre as respostas de pais e mães para os problemas de comportamento variou de baixa a moderada. Tais resultados apontam que pais e mães tendem a não concordar quando solicitados a se pronunciar sobre problemas de comportamento dos filhos. A hipótese para essa discordância refere-se às distintas formas de interação parental.

\section{Consideraçóes finais}

Conforme foi possível verificar no decorrer desta breve discussão, as diversas pesquisas sobre o tema da parentalidade apontam que as mães tendem a se envolver mais do que os pais nas tarefas do dia a dia junto à prole. Do mesmo modo, pesquisas atuais ainda apontam que o trabalho doméstico continua sendo atribuído às mulheres, mesmo quando estas participam ativamente na economia familiar (IBGE, 2006; 2008; Madalozzo, Martins \& Shiratori, 2008; Soares \& Sabóia, 2007). Tal fenômeno resulta em diferentes formas de interação bem como em diferentes percepções de homens e mulheres em relação aos seus filhos(as), em relação às responsabilidades referentes a eles.

A despeito de todas as mudanças ocorridas na sociedade e na família contemporânea, marcadas pela consolidação do papel da mulher no mercado de trabalho e, consequentemente, a necessidade de uma divisão mais igualitária das tarefas referentes à prole e ao lar, ainda existe a crença de que a unidade mãe/filho(a) é básica, universal e psicologicamente mais apropriada para o desenvolvimento saudável da criança do que a relação pai/filho(a). Tal realidade pode ser verificada na quantidade de produções científica sobre o tema.

A literatura específica sobre o tema aponta que as concepções quanto ao lugar de homens e mulheres nas relações familiares são percebidas de maneira distinta. Mesmo passados vinte anos, a literatura ainda apresenta maior número de estudos sobre maternidade, quando comparados aos sobre paternidade. A própria psicologia tem fomentado, ao longo do tempo, a ênfase na relação da díade mãe/criança como primordial nos estudos de desenvolvimento da criança. Dentre as suas diversas correntes teóricas, a produção 
psicanalítica muito contribuiu para fazer da mãe o personagem determinante da saúde ou da doença psíquica da criança.

As mudanças nas configurações familiares, decorrentes das atuais demandas sociais e contemporâneas têm gerado um maior interesse, por parte da sociedade, sobre a importância da figura paterna para a família e, especificamente, para o desenvolvimento da criança. Assim, é importante que as pesquisas da área acompanhem essa demanda, colaborando com novos estudos que possibilitem compreender a relevância das mudanças nas relações parentais e o impacto delas para a família e para a sociedade.

\section{Referências}

Ariès, P. (1981). História social da criança e da família. Rio de Janeiro: Guanabara Koogan.

Badinter, E. (1985). Um amor conquistado: O mito do amor materno. Rio de Janeiro: Nova Fronteira.

Borsa, J. C. (2007). Considerações acerca da relação mãe-bebê da gestação ao puerpério. Revista Contemporânea, 2, abr./maio/jun. Recuperado em 10 jan. 2010, em http:/ / www.contemporaneo.org.br/ artigos/artigo89.pdf

Borsa, J. B., \& Nunes, M. L. T. (2008). Concordância parental sobre problemas de comportamento infantil através do CBCL. Paidéia, 18(40), 317-330.

Bowlby,J. (1989). Uma base segura: Aplicações clínicas da teoria do apego. Porto Alegre: Artes Médicas.

Braz, M. P., Dessen, M. A., \& Silva, N. L. P. (2005). Relações conjugais e parentais: uma comparação entre famílias de classes sociais baixa e média. Psicologia: Reflexão e Crítica, 18(2), 151-161.

Chodorow, N. (1990). Psicanálise da maternidade: Uma crítica a Freud a partir da mulher. Rio de Janeiro: Rosa dos Tempos.

Costa, J. F. (1979). Ordem médica e norma familiar. Rio de Janeiro: Graal.

Crepaldi, M. A., Andreani, G., Hammes, P. S., Ristof, C. D., \& Abreu, S. R. (2006). A participação do pai nos cuidados da criança segundo a concepção de mães. Psicologia em Estudo, 11(3), 579-587.
De Marque, C. R. (2006). Construção de identidade e formação de vínculos, no processo psicoterapêutico de uma criança, em diferentes contextos familiares. Dissertação de Mestrado, Instituto de Psicologia, Universidade de São Paulo, São Paulo.

Duarte, L. F. D. (1995). Horizontes do indivíduo e da ética no crepúsculo da família. In I. Ribeiro \& A. C. T. Ribeiro (Org.). Família em processos contemporâneos: Inovações culturais na sociedade brasileira (pp. 27-41). São Paulo: Loyola.

Favaro, C. (2007). Mulher e família: Um binômio (quase) inseparável. In M. N. Strey, J. A. S. Neto, R. L. Horta (Org.). Família e gênero (pp. 39-56). Porto Alegre: EDIPUCRS.

Flandrin, J. (1992). Família: Parentesco, casa e sexualidade na sociedade antiga. Lisboa: Estampa.

Fleck, A. C., \& Wagner, A. (2003). A mulher como a principal provedora do sustento econômico familiar [Número especial]. Psicologia em Estudo, 8, 31-38.

Frizzo, G. B., Kreutz, C. M., Schmidt, C., Piccinini, C. A., \& Bosa, C. (2005). O conceito de coparentalidade e suas implicações para a pesquisa e para a clínica: Implication for research and clinical practice. Revista Brasileira Crescimento Desenvolvimento Humano, 15(3), 84-93.

Gomes, A. J. S., \& Resende, V. R. (2004). O pai presente: O desvelar da paternidade em uma família contemporânea. Psicologia: Teoria e Pesquisa, $20(2), 119-125$.

Grant, W. H. (2001). A maternidade, o trabalho e a mulher. Proceedings of III Colóquio do Lepsi IP/FE-USP. São Paulo. 2001. Recuperado em 9 Jan. 2010, em http://www.proceedings.scielo.br/ scielo.php?script $=$ sci_arttext\&pid $=$ MSC0000000 032001000300008\&lng $=$ en\&nrm $=$ abn

Instituto Brasileiro de Geografia e Estatística - IBGE. (2006). Estudos e pesquisas - Informação Demográfica e Socioeconômica, n. 19, Síntese dos indicadores sociais. Recuperado em 23 jan. 2010, em http://www.ibge.gov.br/home/estatistica/ populacao/condicaodevida/indicadoresminimos/ sinteseindicsociais2006/indic_sociais2006.pdf 
Instituto Brasileiro de Geografia e Estatística - IBGE (2008). Pesquisa Mensal de Emprego: Principais destaques da evolução do mercado de trabalho nas regiões metropolitanas do Brasil - Recife, Salvador, Belo Horizonte, Rio de Janeiro, São Paulo e Porto Alegre. Recuperado em 22 dez. 2009, em http://www.ibge.gov.br/home/estatistica/indicadores/trabalhoerendimento/pme_nova/Retrospectiva2003_2007.pdf

Kerr, D. C. R., Lunkenheimer, E. S., \& Olson, S. L. (2007). Assessment of child problem behaviors by multiple informants: a longitudinal study from preschool to school entry. Journal of Child Psychology and Psychiatry, 48(10), 967-975.

Lamb, M.E. (1975). Fathers: Forgotten contributors to child development. Human Development, 18, 245-266.

Leite, C. L. P. (1994). Mulheres: Muito além do teto de vidro. São Paulo: Atlas.

Levandowski, D. C. (2001). Paternidade na adolescência: Uma breve revisão da literatura internacional. Estudos de Psicologia, 6(2), 195-209.

Levandowski, D. C., Koller, S. H., \& Piccinini, C. A. (2002). Paternidade na adolescência e os fatores de risco e de proteção para a violência na interação pai-criança. Interações, 8(13), 77-100.

Lévi-Strauss, C. (1972). As estruturas elementares do parentesco. Rio de Janeiro: Vozes.

Luz, A. M. H., \& Berni, N. I. O. (2010). Processo da paternidade na adolescência. Revista Brasileira de Enfermagem, 63(1), 43-50.

Madalozzo, R., Martins, S. R., \& Shiratori, L. (2008). Participação no mercado de trabalho e no trabalho doméstico: Homens e mulheres têm condições iguais? Recuperado em 18 jan. 2010, em http:/ / www. ibmecsp.edu.br/pesquisa/download.php?recid $=3178$

Margolin, G., Gordis, E. B., \& John, R. S. (2001). Coparenting: A link between marital conflict and parenting in two parent-families. Journal of Family Psychology, 15(1), 3-21.
Melo, H. P., Considera, C. M., \& Sabatto, A. D. (2005). Os afazeres domésticos contam. Economia, Textos para Discussão - UFF, 177. Recuperado em 18 jan. 2010, em http://www.uff.br/econ/download/ tds/UFF_TD177.pdf

Minuchin, S. (1982). Famílias: Funcionamento e tratamento. Porto Alegre: Artmed.

Mora, L., Otálora, C., \& Recagno-Puente, I. (2005). Hombre y la mujer frente al hijo: Diferentes voces sobre su significado. Psykhe, 14(2), 119 -132.

Negreiros, T. C. G. M., \& Féres-Carneiro, T. (2004). Masculino e feminino na família contemporânea. Estudos e Pesquisas em Psicologia, 4(1), 34-47.

Nudler, A., \& Romaniuk, S. (2005). Prácticas y subjetividades parentales: Transformarciones e inercias. Revista La Ventana, 3(22), 269-285.

Parke, R. (1998). El papel del padre. Madrid: Morata.

Piccinini, C. A., Silva, M. R., Gonçalves, T. R., Lopes, R. S., \& Tudge, J. (2004). O envolvimento paterno durante a gestação. Psicologia: Reflexão e Crítica, 17(3), 303-314.

Ramires, V. R. (1997). O exercício da paternidade hoje. Rio de Janeiro: Rosa dos Tempos.

Resende, A. L. M. de, \& Alonso, I. L. K. (1995). O perfil do pai cuidador. Revista Brasileira de Crescimento e Desenvolvimento Humano, 5(1/2), 66-81.

Rocha-Coutinho, M. L. (2003). O papel de homens e mulheres na família: Podemos falar em reestruturação? Psicologia Clínica, 15(2), 93-107.

Silva, C. E. (2005). História e desenvolvimento do conceito de família. Dissertação de Mestrado, Pontifícia Universidade Católica de São Paulo, São Paulo.

Silva, M. R., \& Piccinini, C. A. (2007). Sentimentos sobre a paternidade e o envolvimento paterno: Um estudo qualitativo. Estudos de Psicologia, 24(4), 561-573. 
Soares, C., \& Sabóia, A. L. (2007). Tempo, trabalho e afazeres domésticos: Um estudo com base nos dados da Pesquisa Nacional por Amostra de Domicílios de 2001 e 2005, Textos para discussão, n. 21. Rio de Janeiro: IBGE. Recuperado em 2 jan 2010, em http://www.ibge.gov.br/home/ estatistica/populacao/tempo_trabalho_afdom_ pnad2001_2005.pdf

Spitz, R. (2000). O primeiro ano de vida. São Paulo: Martins Fontes. (Original publicado em 1965).

Szymanski, H. (1994). Educação para família: Uma proposta de trabalho preventivo. Revista Brasileira de Crescimento e Desenvolvimento Humano, 1(4), 34-39.

Talbot, J. A., \& McHale, J. P. (2004). Individual parental adjustment moderates the relationship between marital and coparenting quality. Journal of Adult Development, 11(3), 191-205.

Wagner, A., Predebon, J., Mosmann, C., \& Verza, F. (2005). Compartilhar tarefas? Papéis e funções de pai e mãe na família contemporânea. Psicologia Teoria e Pesquisa, 21(2), 181-186.

Winnicott, D. W. (1998). Os bebês e suas mães. São Paulo: Martins Fontes. (Original publicado em 1987).

Winnicott, D. W. (2000). Da pediatria à psicanálise. Rio de Janeiro: Imago. (Original publicado em 1958).

Winnicott, D. W. (2001). A família e o desenvolvimento individual ( $2 \mathrm{a}$ ed.). São Paulo: Martins Fontes. (Original publicado em 1965).

Recebido: 01/02/2010

Received: 02/01/2010

Aprovado: 30/06/2010

Approved: 06/30/2010 